\title{
Temporal attention for visual food stimuli in restrained eaters
}

Citation for published version (APA):

Neimeijer, R. A. M., de Jong, P. J. ., \& Roefs, A. (2013). Temporal attention for visual food stimuli in restrained eaters. Appetite, 64, 5-11. https://doi.org/10.1016/j.appet.2012.12.013

Document status and date:

Published: 01/01/2013

DOI:

10.1016/j.appet.2012.12.013

Document Version:

Publisher's PDF, also known as Version of record

Document license:

Taverne

Please check the document version of this publication:

- A submitted manuscript is the version of the article upon submission and before peer-review. There can be important differences between the submitted version and the official published version of record.

People interested in the research are advised to contact the author for the final version of the publication, or visit the DOI to the publisher's website.

- The final author version and the galley proof are versions of the publication after peer review.

- The final published version features the final layout of the paper including the volume, issue and page numbers.

Link to publication

\footnotetext{
General rights rights.

- You may freely distribute the URL identifying the publication in the public portal. please follow below link for the End User Agreement:

www.umlib.nl/taverne-license

Take down policy

If you believe that this document breaches copyright please contact us at:

repository@maastrichtuniversity.nl

providing details and we will investigate your claim.
}

Copyright and moral rights for the publications made accessible in the public portal are retained by the authors and/or other copyright owners and it is a condition of accessing publications that users recognise and abide by the legal requirements associated with these

- Users may download and print one copy of any publication from the public portal for the purpose of private study or research.

- You may not further distribute the material or use it for any profit-making activity or commercial gain

If the publication is distributed under the terms of Article $25 \mathrm{fa}$ of the Dutch Copyright Act, indicated by the "Taverne" license above, 
Research report

\title{
Temporal attention for visual food stimuli in restrained eaters
}

\author{
Renate A.M. Neimeijer ${ }^{\mathrm{a}, *}$, Peter J. de Jong ${ }^{\mathrm{a}}$, Anne Roefs ${ }^{\mathrm{b}}$ \\ ${ }^{a}$ Department of Clinical Psychology, Faculty of Behavioral and Social Sciences, University of Groningen, Grote Kruisstraat 2-1, 9712 TS Groningen, The Netherlands \\ ${ }^{\mathrm{b}}$ Department of Experimental Psychology, Faculty of Psychology, Maastricht University, P.O. Box 616, 6200 MD Maastricht, The Netherlands
}

\section{A R T I C L E I N F O}

\section{Article history:}

Received 21 August 2012

Received in revised form 11 December 2012

Accepted 14 December 2012

Available online 29 December 2012

\section{Keywords:}

Restrained eating

Attentional bias

Attentional blink

Rapid serial visual presentation task Food

\begin{abstract}
A B S T R A C T
Although restrained eaters try to limit their food intake, they often fail and indulge in exactly those foods that they want to avoid. A possible explanation is a temporal attentional bias for food cues. It could be that for these people food stimuli are processed relatively efficiently and require less attentional resources to enter awareness. Once a food stimulus has captured attention, it may be preferentially processed and granted prioritized access to limited cognitive resources. This might help explain why restrained eaters often fail in their attempts to restrict their food intake. A Rapid Serial Visual Presentation task consisting of dual and single target trials with food and neutral pictures as targets and/or distractors was administered to restrained $(n=40)$ and unrestrained $(n=40)$ eaters to study temporal attentional bias. Results indicated that (1) food cues did not diminish the attentional blink in restrained eaters when presented as second target; (2) specifically restrained eaters showed an interference effect of identifying food targets on the identification of preceding neutral targets; (3) for both restrained and unrestrained eaters, food cues enhanced the attentional blink; (4) specifically in restrained eaters, food distractors elicited an attention blink in the single target trials. In restrained eaters, food cues get prioritized access to limited cognitive resources, even if this processing priority interferes with their current goals. This temporal attentional bias for food stimuli might help explain why restrained eaters typically have difficulties maintaining their diet rules.
\end{abstract}

(c) 2012 Elsevier Ltd. All rights reserved.

\section{Introduction}

The prevalence of obesity has tripled in many countries of the WHO European Region since the 1980s, and the numbers of those affected have risen at an alarming rate. Because obesity is the result of a chronic imbalance between energy intake and energy expenditure, dieting is a logical strategy to lose weight. However, not many dieters are able to maintain their initial weight loss over a longer period of time (Elfhag \& Rössner, 2010; Jeffery et al., 2000). As soon as they quit dieting, many dieters even gain more weight than they initially lost (Mann et al., 2007). People with a chronic intention to lose weight are called restrained eaters (Herman \& Polivy, 1980). Although restrained eaters are very motivated to control their weight by dieting, they are often unsuccessful in these attempts, and their eating behavior is characterized by alternating periods of restraint and bouts of overeating (Gorman \& Allison, 1995).

Biased processing of food cues might be one of the mechanisms involved in restrained people's difficulty to control their food intake. Germane to this, it has been proposed that there is a reciprocal relationship between selective attention for food cues (attentional

\footnotetext{
* Corresponding author.

E-mail addresses: R.A.M.Neimeijer@rug.nl (R.A.M. Neimeijer), P.J.de.Jong@rug.nl (P.J. de Jong), A.Roefs@Psychology.Unimaas.nl (A. Roefs).
}

bias) and craving (Franken, 2003). Following this view, attentional bias would lead to craving for food, whereas in its turn, enhanced craving would again strengthen the attentional bias for food. Accordingly, people may end up in a self-reinforcing cycle, which will logically undermine their attempts to restrict their food intake.

However, previous studies, using various paradigms to measure attentional bias, largely failed to find evidence for the hypothesized heightened vigilance toward high caloric food items in restrained eaters. Originally, the Stroop paradigm was often used. Previous studies using this paradigm in the context of restrained eaters found mixed evidence for color naming interference effects for food words compared to neutral words (see for a review: Dobson \& Dozois, 2004). However, the use of Stroop tasks in research for attentional bias is debatable, because the color-naming interference effects can be the result of both heightened attention for food related material as well as avoidance of food-related material (De Ruiter \& Brosschot, 1994). A recent study used a modified version of the Stroop task to distinguish between orientation and disengagement and found that restrained eaters had no orientation bias but showed a slowed disengagement for food cues as well as for ego threat cues (Wilson \& Wallis, 2012). Furthermore, studies used also other more straightforward indices of (spatial) attention such as the visual probe task. However, studies using visual probe tasks failed to find evidence for heightened attention towards (or away from) food words (Boon, Vogelzang, \& Jansen, 2000) or food 
pictures (Ahern, Field, Yokum, Bohon, \& Stice, 2010) in restrained eaters. Likewise, a study using an exogenous cuing task with food pictures also failed to find an attentional bias for food stimuli in restrained eaters (Veenstra, de Jong, Koster, \& Roefs, 2010). Finally, a study employing a visual search task did show that restrained eaters were faster in detecting a food word in a neutral matrix. However, restrained eaters were also faster in detecting neutral words in a food matrix (Hollitt, Kemps, Tiggemann, Smeets, \& Mills, 2010).

In sum, previous research provided no straightforward support for the hypothesized role of attentional bias in restrained eaters' failure to regulate their caloric intake. However, all of these earlier studies on attentional bias in restrained eating exclusively focused on spatial selective attention. Importantly, attention is not only distributed over space, but also over time. The privileged processing of food cues may be especially prominent in the temporal dimension. For example, it could be that for restrained eaters food stimuli are processed relatively efficiently and require less attentional resources (lower threshold) to enter people's awareness. Once a food stimulus has captured attention, it may be preferentially processed and granted prioritized access to limited cognitive resources (cf. Koster, De Raedt, Verschuere, Tibboel, \& De Jong, 2009). Such privileged access may not only prevent new information from entering working memory, but may also provide the opportunity for more elaborate processing of the food stimulus. This is in line with the 'elaborated intrusion theory of desire', that states that intrusive thoughts about appetitive targets are triggered automatically by external cues. When intrusions elicit significant pleasure or relief, this will usually promote cognitive elaboration. Elaboration competes with concurrent cognitive tasks through retrieval of target related information and its retention in working memory (Kavanagh, Andrade, \& May, 2005). External cues of 'forbidden food' might have this same effect for restrained eaters. Finally, food cues might not only receive processing priority when people are actively looking for food cues (top down controlled), but may also more automatically attract attention (bottom up), even at the expense of current task performance (Piech, Pastorino, \& Zald, 2009). Thus far, the potential role of the temporal dimension of attentional bias in restrained eating has been largely ignored. Further insight into the temporal dynamics of attention for food stimuli may help explain why restrained eaters may experience difficulty in regulating their food intake. Therefore, the aim of the current study is to test whether temporal attentional bias might indeed be involved in restrained eating.

A task often used to measure temporal attention is the Rapid Serial Visual Presentation task (RSVP), in which stimuli are presented sequentially without inter-stimulus interval (e.g., $118 \mathrm{~ms} /$ stimulus) on a computer screen. In every stream of pictures one or two targets appear, that have to be identified after each stream. The lag (time) between the two targets can be manipulated. Basic research in the temporal dimension of visual attention has consistently shown that the ability to identify a particular target is deteriorated when another target is presented in close temporal proximity $(<500 \mathrm{~ms})$. The deficit in the identification of the second target (T2) has been called the attentional blink, referring to the apparent refractory period following the presentation of the preceding target (T1). When the interval (lag) between the targets increases ( $>500 \mathrm{~ms}$ ), T2 performance is no longer hampered (Fig. 1).

Temporal attentional bias can be expressed in at least four different ways within the context of a RSVP task: (1) Attentional blink can be diminished (magnitude of attentional blink is reduced) when T2 is a salient cue (e.g., food stimulus), and therefore T2 will be identified despite the preceding T1. (2) The appearance of a salient T2 (e.g., food) may interfere with the correct identification of a preceding T1 (backward interference). (3) Attentional blink can be enhanced when $\mathrm{T} 1$ is a salient cue and, therefore, the attentional blink will last longer than the usual attentional blink (500 ms). (4) An attentional blink can be elicited when a salient task-irrelevant distractor (e.g., food) is presented shortly before the actual target. The distractor can be ignored but may nevertheless induce an attentional blink. In the following each of these four types of temporal attentional bias will be addressed in more detail.

First, it has been shown that the attentional blink is diminished (i.e., higher identification rates of T2) when the T2 is of high personal relevance (e.g., the participant's name: Shapiro, Caldwell, \& Sorensen, 1997). To explain this reduced attentional blink effect, it has been argued that highly salient stimuli are processed relatively efficiently thereby lowering the threshold for accurate identification, even when only little attentional resources are available. To the extent that food cues are highly salient for participants, also food stimuli may diminish the attentional blink, thereby heightening the probability that food items will enter people's awareness. The present study will examine whether indeed food stimuli, as compared to neutral stimuli, are more easily identified (diminish the attentional blink) when presented as T2, and whether this might be especially the case for restrained eaters.

Second, there is evidence that the appearance of a salient T2 may interfere with the correct identification of a preceding $\mathrm{T} 1$ (i.e., lower identification rates of T1), this backward interference effect has also been called a 'backward blink' (Potter, Staub, \& O'Connor, 2002). For example, when a T2 is presented very shortly after a T1, T2 has even been found to be correctly identified more often than the preceding T1 (Potter, Staub, \& O'Connor, 2002). There might as well be an interference effect of food T2 targets on $\mathrm{T} 1$ identification for restrained eaters.

Illustrating the third type of temporal attentional bias, that attentional blink can be enhanced by a salient T1, (i.e., lower identification rates of $\mathrm{T} 2$ ), it has been shown that negative self-descriptors as $\mathrm{T} 1$ resulted in an enhanced attentional blink in dysphoric participants (Koster et al., 2009). A similar T1-enhanced attentional blink effect has been shown when angry faces were presented as T1 (de Jong, Koster, van Wees, \& Martens, 2010). Thus, it appears that self-relevant salient stimuli elicit more elaborate processing, which is reflected in the associated temporal attention costs. In a similar vein, it can be hypothesized that specifically for restrained eaters, food stimuli might also receive more elaborate processing thereby enhancing the attentional blink.

The fourth type of temporal attentional bias refers to the phenomenon that also task irrelevant distracters may elicit an attentional blink (i.e., lower identification rates of a target presented after the distractor). In the typical attentional blink tasks people have to identify two targets, which are presented in a stream. Hence, the content of the stimuli (e.g., food) is typically a task relevant stimulus feature. If food items are used as T1 or T2, this implies that people are instructed to actively search for food stimuli. However, it is also important to verify whether food items may also attract attention when they are task-irrelevant. In other words, also when people are not intentionally searching for food stimuli, such stimuli may nevertheless elicit an attentional blink. To assess such processing priority of food stimuli, food cues may be used as task-irrelevant distractors in a single target RSVP. Germane to this, it has been shown that positive arousing pictures (nudes of the preferred sex) as a task irrelevant distractor stimulus, can elicit an attentional blink when presented close to the target slide (Most, Smith, Cooter, Levy, \& Zald, 2007). Interestingly, this preferential processing of task-irrelevant distractors (the nude stimuli) was evident despite a strong incentive to ignore the task-irrelevant distractor. This is therefore assumed to reflect more automatic (non-intentional) attentional processes. In a similar vein, it could be that food items may attract attention even if these items are irrelevant for people's current goals. Therefore, the present study also included a third type of RSVP trials, that were 


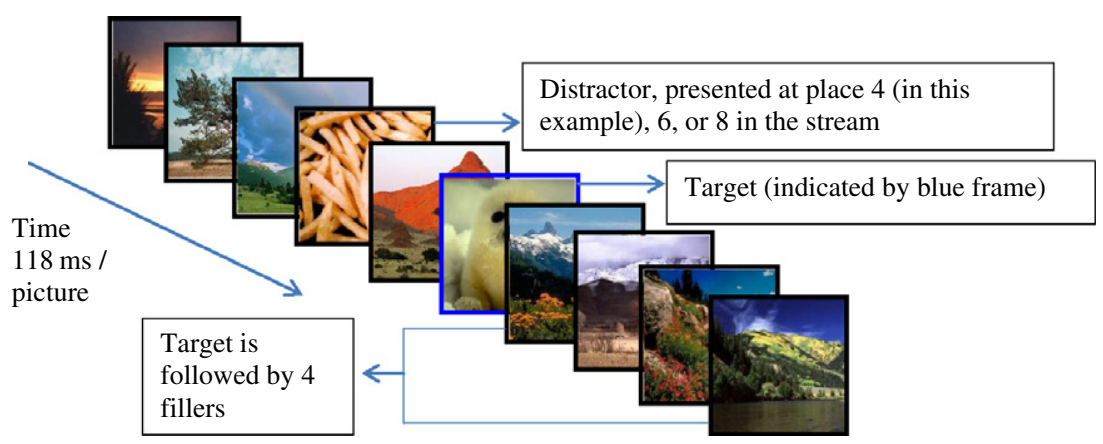

Fig. 1. Example of a single target trial (third type of RSVP trials), lag 2 .

designed to test whether indeed especially in high restrained individuals, food distractors would elicit an attentional blink even in a context that motivates to ignore these stimuli (i.e., to optimize task performance).

\section{Present study}

The present experiment covers the four types of temporal attentional bias in three types of RSVP trials that were discussed above and was designed to investigate the temporal characteristics of attentional bias in the context of restrained eating. In short, the study tested the following hypotheses involving restrained eaters:

(i) The attentional blink is diminished when T2 is a food stimulus;

(ii) food $\mathrm{T} 2 \mathrm{~s}$ interfere with correct identification of a preceding neutral target (backward interference); (iii) the attentional blink is enhanced with food T1s, and (iv) task-irrelevant food cues elicit an attentional blink. Therefore, we subjected a group of participants with varying food-restrain tendencies to these three variants of RSVP tasks.

\section{Method}

\section{Participants}

Participants were first year female psychology students of the University of Groningen $(n=80)$. All participants gave their written informed consent to take part. By means of a median split of the Restraint Scale (RS: Herman \& Polivy, 1980), participants were divided into a group of high and a group of low restrained eaters. Participants scoring higher than $10(n=40)$ were classified as restrained eaters (BMI: $M=23.45 ; S D=2.62$; range $=18.83-30.09$, age: $M=20.1$; $S D=1.88$; range $18-24)$. Participants scoring 9 or lower on the RS $(n=40)$ were classified as low restrained eaters (BMI: $M=21.18, S D=2.18$, range $=16.63-27.28$, age: $M=22.3$; $\mathrm{SD}=5.21$; range 18-48). High RS participants had a higher BMI than low RS participants, $t(78)=4.21, p<.01$.

\section{Materials}

RSVP

The task was performed on a Windows XP computer with a 22in. monitor (resolution set to 1280 by 1024 pixels), and was programmed in E-prime 2.0 (Schneider, Eschman, \& Zuccolotto, 2002). Experimental trials consisted of a Rapid Serial Visual Presentation (RSVP) stream, with 1 or 2 critical stimuli (T1 and T2) in each stream. In a trial were, dependent on the place of the first target and the lag, 10-19 pictures shown for $118 \mathrm{~ms}$ each without inter-stimulus interval. The last target was always followed by a fixed number of four fillers, to ensure that any differences in results across types of trials could not be attributed to a variable time the final target had to be kept in working memory. The order of the trials, as well as which pictures were paired with which lag were individually randomized.

\section{First type of RSVP trials}

To test hypothesis 1 , that attentional blink is diminished by a food $\mathrm{T} 2$ and hypothesis 2 , that a food $\mathrm{T} 2$ have an interference effect on participants' ability to identify T1, a dual target task was designed. In this task, T1 (always neutral) was randomly presented on one of three possible positions in the stream $(4,6,8)$. T2 (food/neutral) was randomly presented at lag 2, 3, 4 or 7 following $\mathrm{T} 1$. Each combination of $\mathrm{T} 1$ position and $\mathrm{T} 2$ position was presented equally often. In the present set up there were 3 (T1 position: 4,6 , $8) \times 4($ lag: $2,3,4,7) \times 2(\mathrm{~T} 2$ : food, neutral $)=24$ different types of trials, each presented six times. For hypothesis 1 , percentage correct $\mathrm{T} 2 \mathrm{~s}$ were calculated as a function of T2 type. Only trials with correct T1 identification were included. For hypothesis 2, percentage correct $\mathrm{T} 1 \mathrm{~s}$ as a function of $\mathrm{T} 2$ type were calculated. To retain sufficient trials, all trials were included, regardless of (accurate) T2 identification.

\section{Second type of RSVP trials}

To test hypothesis 3, that food T1's can enhance the attentional blink, another dual target task was designed. This type of RSVP trials are similar to the first type of RSVP trials, with the only difference being that T1 is either food or neutral and T2 always neutral. This resulted in a total of 24 different types of trials from which 12 overlapped with the first type of RSVP trials (T1 neutral and T2 neutral), each presented six times. Percentage correct T2's as a function of T1 were calculated. Only trials with correct T1 identification were included.

\section{Third type of RSVP trials}

To test hypothesis 4, that food distractors can elicit an attentional blink even when task irrelevant, a single target task was designed. To test the specificity of this food-distraction effect, we also included threatening stimuli as distractors in addition to the neutral (control) and food-related distractors. The distractor was randomly presented on one of three possible positions in the stream $(4,6,8)$. The target was randomly presented at lag 2 or 8 following the distractor. In the present setup there were 3 (type of distractor: food, threat, neutral) $\times 3$ (T1 position: $4,6,8) \times 2$ (lag: 2,8$)=18$ different types of trials, each presented six times. Percentage correct T's as a function of distractor were calculated.

\section{Stimuli}

Stimuli, measuring $550 \times 550$ pixels, were photographs: 46 high caloric food stimuli, 39 threatening stimuli, 57 neutral 
pictures and 75 fillers (landscapes). The neutral and threat pictures were taken from the International Affective Picture System (IAPS). Food pictures were purchased on Istockphoto. Neutral pictures consisted of people, animals and everyday objects like money, a book, and shoes (see Appendix 1). Food pictures consisted of a wide range of high caloric palatable food pictures, like fries, a burger, cake, chocolate, and a pizza. Threatening pictures were of people or animals and consisted of medical trauma, distress, and violence (see Appendix 1). Target pictures had a 10-pixel blue frame, while all other stimuli had a 10 pixel black frame. During the entire series of RSVP trials, each single picture was presented for approximately five times.

\section{Visual analogue scales for food liking, craving, and consumption}

Participants assessed the liking of food items of the RSVP by answering the question: 'How much do you like this product' using a visual analogue scale (VAS) from 0 (not at all) to 100 (very much). Craving was measured using the question: 'How much do you crave for this product at this moment?', which was rated on a VAS ranging from 0 (not at all) to 100 (very much). Furthermore, participants were asked to assess the frequency with which they ate the particular food using the question 'How frequently do you eat this product', which was answered on a VAS ranging from 0 (not at all) to 100 (very much).

\section{Hunger scale}

The Hunger Scale (HS: Grand, 1968) consists of hunger items (time since last eating, subjective hunger, estimate of the amount of favorite food able to eat, estimate of time until next expected meal) and was administered to control for the influence of hunger. Scores on the four items were combined to form a composite hunger index. High scores refer to hunger or deprivation from food.

\section{Restraint scale}

The Restraint scale (Herman \& Polivy, 1980) consists of 10 items and was used to measure the participant's intention to diet. Values can range from 0 to 35 , with higher scores reflecting a stronger intention to restrain. Test-retest reliability is high $(r=0.95)$ and internal consistency has been estimated at $\alpha=.82$ (Allison, Kalinsky, \& Gorman, 1992). It is assumed that the Restraint Scale identifies "unsuccessful" dieters who have a higher tendency toward overeating (van Strien, Herman, Engels, Larsen, \& van Leeuwe, 2007).

\section{Procedure}

After signing informed consent, the RSVP was administered. A participant started with a 20 -trials practice session. Hereafter, a total number of 324 trials were presented in three similar blocks of 108 trials, with a $30 \mathrm{~s}$ break following each block to reduce the influence of fatigue and problems with participants' concentration. Trials of all three described RSVP types were presented intermixed, in a unique random order for each participant. After each trial, participants were asked how many pictures they had seen with a blue frame (targets) and what the content of these pictures was. They gave their answer verbally to the experimenter, who, in turn, indicated on a response box whether the answer was correct and specific. If the response was not sufficiently specific, the experimenter asked for clarification. After the RSVP the VAS, RS, and HS were filled out. Finally, height and weight were measured. During the task participants were not allowed to eat or drink.

\section{Results}

\section{Group characteristics}

Restrained and unrestrained eaters did not differ in their selfreported frequency of high-fat food consumption, $t(78)=1.45$, $p=.15$. They also did not differ with respect to their current motivational state of hunger, $t(78)=0.99, p=.32$, which rules out the influence of hunger as an explanation of potential group differences. Restrained and unrestrained eaters did not differ in their self-reported craving for high-fat food, $t(78)=1.22, p=.23$ or liking of high-fat food, $t(78)=0.53, p=.56$.

\section{Do food T2 stimuli diminish the attentional blink specifically for restrained eaters? (first type of RSVP trials)}

Mean percentages correctly identified T2s are presented in Table 1 as a function of T2 type, lag and group. The number of correctly identified T2's were subjected to a 4 (lag: $2,3,4,7) \times 2$ (T2 type: food, neutral) $\times 2$ (group: restrained, unrestrained) mixed ANOVA. There was a significant main effect of lag, $F(3,234)=387.11, p<.01, \eta_{p}^{2}=.83$, indicating that participants showed an attentional blink when the time-lag between T1 and T2 was small (lags 2 and 3), whereas the blink almost disappeared when the time-lag was large (lag 7). This is consistent with earlier research in the temporal dimension of visual attention. Contrasts indicated that every lag differed significantly from the previous lag (lag 2 vs. lag 3: $F(1,78)=490.11, p<.01, \eta_{p}^{2}=.86$, lag 3 vs. 4 , $F(1,78)=76, p<.01, \eta_{p}^{2}=.49$, lag 4 vs. lag $7, F(1,78) 18.39$, $p<.01, \eta_{p}^{2}=.19$. Thus, the longer the time-interval between T1 and $\mathrm{T} 2$, the higher the frequency of correct T2 identifications. This effect was similar for food and neutral T2s and independent of group, as was evidenced by the absence of a lag $\times$ T2 type interaction, $F(3,234)=1.09, p=.36$ and a lag $\times$ group interaction, $F(3,234)=1.63, p=.18$ respectively. In contrast to hypothesis 1 , neutral T2's were generally more often correctly identified than food T2s as was evidenced by a main effect of T2 type, $F(1,78)=10.06, p<.01, \eta_{p}^{2}=.11$. There was no expected significant T2 type $\times$ group interaction effect, $F(1,78)=.17, p=.68$, neither a T2 type $\times$ group $\times$ lag interaction, $F(3,234)=.77, p=.51$ indicating that this effect was similar for restrained and unrestrained eaters.

Do food T2 stimuli have a relatively strong interference effect on correct identification of neutral T1 specifically in restrained eaters (backward interference, first type of RSVP trials)?

Mean percentage correctly identified neutral T1s are presented in Table 2 as a function of T2 type, lag and group. The number of correctly identified T1's were subjected to a 4 (lag: $2,3,4,7) \times 2$ (T2: type: food, neutral) $\times 2$ (group: restrained, unrestrained) mixed ANOVA. There were no main effects of lag, $F(3,234)=.62$, $p=.60$ and T2 type, $F(1,78)=1.23, p=.37$. However, there was a significant T2 type $\times$ group interaction, $F(1,78)=4.3, p=.04$, $\eta_{p}^{2}=.05$, independent of lag, $F(3,234)=1.35, p=.26$. Post hoc $t$-tests showed that the restrained eaters tended to correctly

Table 1

Percentage correctly identified T2's as a function of T2 type.

\begin{tabular}{llllll}
\hline & Restrained & & & Unrestrained & \\
\cline { 2 - 3 } \cline { 5 - 6 } & T2 food & T2 neutral & & T2 food & T2 neutral \\
\hline Lag 2 & $24.4(18.4)$ & $30.1(17.7)$ & & $30.2(20.2)$ & $35.0(23.9)$ \\
Lag 3 & $58.8(20.6)$ & $64.6(18.3)$ & & $65.4(16.9)$ & $67.8(19.3)$ \\
Lag 4 & $74.0(17.7)$ & $77.1(14.8)$ & & $78.8(14.9)$ & $79.4(14.3)$ \\
Lag 7 & $83.8(13.9)$ & $83.5(13.7)$ & & $80.7(10.3)$ & $83.9(16.5)$ \\
\hline
\end{tabular}


identify a lower percentage of T1's with food T2s than with neutral T2s, $t(39)=1.98, p=.06$, whereas a similar interference effect of food T2 was absent in unrestrained eaters, $t(39)=.86, p=.39$. Thus, in line with hypothesis 2 , specifically in restrained eaters food T2 tended to show an interference effect which was independent of lag.

Do food $T 1$ stimuli enhance the attentional blink specifically in restrained eaters (second type of RSVP trials)?

In this variant correctly identified T2s after two types of T1 (food or neutral) were examined (see Table 3). A 4 (lag: 2, 3, 4, $7) \times 2$ (T1 type: food, neutral $) \times 2$ (group: restrained, unrestrained) mixed ANOVA showed a main effect of lag, $F(3,234)=362.51$, $p<.01, \eta_{p}^{2}=.82$ indicating that participants showed an attentional blink when the time-lag between T1 and T2 was small (lags 2 and 3 ), whereas the blink almost disappeared when the time-lag was large (lag 7). Contrasts revealed that every lag differed from the previous lag (lag 2 vs. lag 3: $F(1,78)=352.38, p<.01, \eta_{p}^{2}=.82$, lag 3 vs. $4 F(1,78)=97.06, p<.01, \eta_{p}^{2}=.56$, lag 4 vs. lag 7 $\left.F(1,78)=34.67, p<.01, \eta_{p}^{2}=.31\right)$. Thus the longer the lag, the more correct identifications. Most relevant for the present context, there was a main effect of T1 type, $F(1,78)=39.62, p<.01, \eta_{p}^{2}=.38$. Participants showed generally more difficulties to identify T2s after a food $\mathrm{T} 1$ than after a neutral T1. This effect varied as a function of lag, as was evidenced by a significant lag $\times \mathrm{T} 1$ type interaction, $F(3,234)=6.30, p<.01, \eta_{p}^{2}=.08$. Post hoc paired sample $t$-tests showed that for all lags except for lag 7 more T2 identification errors were made when $\mathrm{T} 1$ was food than when $\mathrm{T} 1$ was neutral, all ts $>$ (79) 2.62 , all $p$ 's $<.01$, lag $7, t(79)=.56, p=.58$, indicating that the influence of T1 on T2 is diminished after a longer time-lag. There was neither a significant $\mathrm{T} 1$ type $\times$ group $F(1,78)=.37$, $p=.55$, nor a T1 type $\times$ group $\times$ lag interaction, $F(3,234)=.94$, $p=.42$, indicating that high and low restrained eaters had similar difficulties identifying T2s following a food T1. Thus in apparent conflict with hypothesis 3, the food-induced attentional blink was not especially pronounced for high restrained eaters.

\section{Do task-irrelevant food distractors elicit an attentional blink} specifically in restrained eaters (third type of RSVP trials)?

Mean percentages of correctly identified neutral Targets after a neutral, food or threat distractor are presented in Table 4. A 2 (lag: $2,8) \times 3$ (distractor type: threat, neutral, food) $\times 2$ (group: restrained, unrestrained) mixed ANOVA showed a main effect of lag, $F(1,74)=42,98, p<.01, \eta_{p}^{2}=.82$. Participants were overall more accurate in identifying targets when presented at lag 8 than at lag 2 following the distractor stimulus. Thus, presenting a taskirrelevant distractor elicited an attentional blink. This effect was independent of group as evidenced by the absence of a lag $\times$ group interaction, $F(1,78)=0.74, p=.39$. Interestingly, there was a main effect of distractor type, $F(2,156)=6,71, p<.01, \eta_{p}^{2}=.11$. Replicating previous research, threat stimuli generally resulted in a larger blink (i.e., lower accuracy rates) than neutral stimuli, $F(1,70)=7.73, p<.01, \eta_{p}^{2}=.11$, which indicates that participants

Table 2

Percentage correctly identified T1's as a function of T2 type.

\begin{tabular}{llllll}
\hline & \multicolumn{2}{l}{ Restrained } & & & \multicolumn{2}{l}{ Unrestrained } \\
\cline { 2 - 3 } \cline { 6 - 6 } & T2 food & T2 neutral & & T2 food & T2 neutral \\
\hline Lag 2 & $88.3(10.7)$ & $89.9(10.0)$ & & $88.1(12.6)$ & $87.1(12.6)$ \\
Lag 3 & $88.8(12.5)$ & $88.6(10.1)$ & & $87.5(12.7)$ & $89.3(10.4)$ \\
Lag 4 & $89.3(10.6)$ & $90.6(9.8)$ & & $89.4(8.5)$ & $87.4(10.1)$ \\
Lag 7 & $87.9(12.2)$ & $91.4(7.5)$ & & $89.4(8.4)$ & $88.4(10.0)$ \\
Overall & $88.6(9.5)$ & $90.1(7.0)$ & & $88.6(8.3)$ & $88.1(8.6)$ \\
\hline
\end{tabular}

Table 3

Percentage correctly identified T2's, as a function of T1 type.

\begin{tabular}{llllll}
\hline & Restrained & & & Unrestrained & \\
\cline { 2 - 3 } \cline { 5 - 6 } & T1 food & T1 neutral & & T1 food & T1 neutral \\
\hline Lag 2 & $24.4(21.2)$ & $30.1(17.7)$ & & $27.9(25.1)$ & $35.0(23.9)$ \\
Lag 3 & $50.7(21.3)$ & $64.6(18.3)$ & & $60.2(19.1)$ & $67.8(19.3)$ \\
Lag 4 & $73.9(19.3)$ & $77.1(14.8)$ & & $74.4(14.7)$ & $79.4(14.3)$ \\
Lag 7 & $84.0(11.5)$ & $83.5(13.7)$ & & $85(12.4)$ & $83.9(16.5)$ \\
\hline
\end{tabular}

were distracted most by threat cues. There was no overall difference between neutral and food distractors, $F(1,78)=.04, p=.83$, but the percentage correct identification after threat was lower than after food, $F(1,78)=9.43, p \leqslant .01, \eta_{p}^{2}=.108$. Most important for the present context, there was a significant distractor type $\times$ group interaction, $F(2,156)=3.61, p=.03, \eta_{p}^{2}=.12$, that appeared independent of lag, $F(2,156)=0.93, p=.40$. Contrasts indicated that for restrained eaters percentage correct after food distractors was lower than after neutral distractors, $F(1,78)=9.48, p=.03, \eta_{p}^{2}=.11$, whereas a similar difference was absent for unrestrained eaters, $F(1,78)=0.06, p=.81$. This is in line with hypothesis 4 and indicates that restrained eaters made, independent of lag, more errors in identifying neutral targets after a food distractor than after neutral distractors, whereas this was not the case for unrestrained eaters. There was no interaction between threat and neutral, and restraint status, $F(1,78)=0.06$, $p=.81$, indicating that restrained eaters are not in general more distracted by salient cues. Furthermore, there was a lag $\times$ distractor type interaction, $F(2,156)=6.52, p<.01, \eta_{p}^{2}=.08$, indicating that the main effect of lag differed per type of distractor. Contrasts revealed that the effect of lag for threat differed from both neutral, $F(1,78)=7.71, p<.01, \eta_{p}^{2}=.09$ and food, $F(1,78)=9.10, p<.01$, $\eta_{p}^{2}=.11$, indicating that the effect of lag was most pronounced in the threat condition.

\section{Discussion}

The present study was designed to investigate temporal attentional bias for high caloric food in restrained and unrestrained eaters. The major results can be summarized as follows: (i) The attentional blink was not diminished with a food T2 as compared to a neutral T2. The percentage correctly identified food T2's was even lower than that of correctly identified neutral T2's. (ii) Specifically for high restrained eaters, there was an interference effect of a food T2 on identifying the preceding neutral T1. That is, the percentage of correctly identified $\mathrm{T} 1 \mathrm{~s}$ was generally reduced with a food T2 as compared to a neutral T2. (iii) Independent of restraint status, the attentional blink was enhanced with a food T1 as compared to a neutral T1. That is the percentage of correctly identified T2s was lower with food T1s as compared to neutral T1s. (iv) Specifically in restrained eaters, task-irrelevant food cues (i.e., distractors) elicited an attentional blink. That is, for restrained eaters, neutral targets were less often correctly identified when they were preceded by a food-related as compared to a neutral distractor.

Attentional bias in the temporal dimension may consist of various components, and each of these components may play a role in the frequent undermining of dieting in restrained eaters. First, the attentional blink may be diminished when food cues appear. As a result, food cues will be identified relatively frequently. The present findings provided, however, no evidence to support this hypothesis that especially in high restrained eaters food cues would diminish the attentional blink. That is, neither high nor low restrained eaters showed a lowered threshold for identification of food cues. Disinhibited eating in restrained eaters can therefore not be explained by relatively efficiently processing of food cues. In fact, neutral cues were even more often identified than food cues. One explanation 
Table 4

Correctly identified T2's as a function of type of distractor (D).

\begin{tabular}{|c|c|c|c|c|c|c|}
\hline & \multicolumn{3}{|l|}{ Restrained } & \multicolumn{3}{|c|}{ Unrestrained } \\
\hline & D: threat & D: food & D: neutral & D: threat & D: food & D: neutral \\
\hline Lag 2 & $81.4(16.5)$ & 85.7 (12.7) & $86.5(11.4)$ & 78.9 (19.6) & $87.6(9.9)$ & 85.7 (9.3) \\
\hline Lag 8 & $90.0(8.4)$ & $87.9(10.5)$ & $91.8(8.3)$ & 90.6 (10.3) & $93.1(7.6)$ & $89.6(11.1)$ \\
\hline
\end{tabular}

for this finding could be that the neutral category is semantically more heterogeneous than the food category. The former one is showing diverse human and non-human content and having also more pictures in its set. In turn, a more homogeneous target category (as the food picture set) is likely to produce more retrieval errors at post-trial report than a category with highly distinctive exemplars (as the neutral category). To test this post hoc explanation, in future research a comparison could be made between the within-category intrusion errors of the two categories of stimulus sets.

It seems worth noting that here is a similarity between spatial attentional bias tasks and the first type of RSVP trials of the current study (neutral T1, food vs. neutral T2). Both types of tasks examine efficient processing of food cues, which would facilitate the detection and/or identification of food cues. In the RSVP it could be that a food T2, as compared to a neutral T2, would be detected more easily, profiting from enhanced access to the cognitive system. The absence of a reduced attentional blink for food cues in the present temporal attention task seems therefore consistent with the previous failure to find differences between restrained and unrestrained eaters in spatial attention tasks such as the visual probe task and the exogenous cueing task (Ahern et al., 2010; Boon et al., 2000; Veenstra et al., 2010).

Second, another type of temporal attentional bias is the interference effect of a T2 on the identification of the preceding T1. In line with hypothesis 2 , specifically in high restrained eaters food cues showed such an interference effect when presented as T2. High restrained eaters showed lower identification rates of $\mathrm{T} 1$ when a food $\mathrm{T} 2$, as compared to a neutral $\mathrm{T} 2$, was presented shortly afterwards. This is in line with previous research, which showed that T2 can have a detrimental influence on the identification of a preceding T1 (Potter, Staub, \& O'Connor, 2002). If two targets are presented in close proximity of each other, food cues might win the competition for attention because they receive prioritized access to limited attentional resources and/or are processed more elaborately in high restrained eaters, thereby overriding the previously encoded $\mathrm{T} 1$.

The third type of temporal attentional bias reflects the impact of prioritized processing of a T1 on people's ability to identify the T2. Supporting the view that food cues will receive prioritized processing that comes at the cost of lowering people's ability to identify subsequently presented target stimuli (cf. de Jong et al., 2010), both restrained and unrestrained eaters showed an enhanced attentional blink with a food $\mathrm{T} 1$ as compared to a neutral T1. This finding is in line with the elaborated intrusion theory of desire, which proposes that attention for food cues can automatically trigger intrusive thoughts. These thoughts compete with concurrent cognitive tasks through retrieval of food-related information and its retention in working memory (Kavanagh et al., 2005). However, considering that the food-induced enhanced attentional blink was not especially pronounced in high restrained eaters, this effect seems not crucially involved in high restrained eaters' difficulty to maintain their diet regimen.

Finally, the fourth type of temporal attentional bias that was examined concerns the influence of task irrelevant cues (i.e., distractors) on people's ability to identify a subsequent neutral target. Previous research (Most, Chun, Widders, \& Zald, 2005; Most et al., 2007) has shown that both positively and negatively valenced salient distractors such as nudes of the preferred sex or threat cues, may elicit an attentional blink (i.e., lower identification rates of a subsequent target). The current results indicated that specifically in restrained eaters, food distractors elicit an attentional blink. Thus even when food cues were presented as task-irrelevant distractors, these food cues nevertheless received prioritized processing in high restrained eaters. In other words, specifically in restrained eaters food items attracted attention even though these items were irrelevant for their current goal. Such nonintentional (bottom up) tendency to prioritize the processing of food cues may help explain why restrained eaters fail so often despite their strong intention to lose weight.

If indeed the relatively strong food-induced attentional blink in high restrained eaters reflects a tendency to prioritize the processing of food stimuli, one may wonder why a similar difference between high and low restrained eaters was absent for the third type of temporal attentional bias measured, in which food cues were presented as T1 (and neutral cues as T2). Note, however, that for this third type, participants were explicitly instructed to identify food (and neutral) targets that were presented in the streams. Such explicit instruction to identify food cues might well have induced a processing strategy in low restrained eaters that is normally restricted to high restrained eaters. Thus, under condition of a top down search for food stimuli the differential tendencies to assign processing priority to food cues may well disappear.

Independent of restraint status, people generally showed lower accuracy rates in detecting a target when preceded by a threat distractor. These findings are consistent with previous research showing that participants frequently fail to identify targets that are presented in close temporal proximity of an emotionally negative picture (Most et al., 2005). The pattern of results indicates that high restrained eaters do not show an overall increased distractibility for salient cues.

The results of the four types of RSVP trials suggest that dieting may be undermined by processes after the initial identification of food cues, rather than by relatively efficient processing of food cues. That is, the pattern of results seem to indicate that food stimuli elicit more elaborate processing in high than in low restrained eaters, which is reflected in the associated temporal attention costs. Accordingly, high restrained eaters showed an enhanced attentional blink following task relevant as well as task irrelevant food cues, and showed relatively poor performance in identifying neutral T1's when followed by food T2's. So specifically in high restrained eaters, food cues have a backward as well as a forward influence (even for task irrelevant cues), implying that food cues remain relatively long in working memory. In its turn, this may give rise to craving and eventually to food intake.

To conclude, the current study was designed to investigate the role of temporal attentional bias in restrained eating. As the most critical finding the results showed that specifically in high restrained eaters, food cues get prioritized access to limited cognitive resources, even if this processing priority interferes with their current goals. This temporal attentional bias for food stimuli might help explain why high restrained eaters typically have difficulties in maintaining their diet rules (Franken, 2003). 


\section{References}

Ahern, A. L., Field, M., Yokum, S., Bohon, C., \& Stice, E. (2010). Relation of dietary restraint scores to cognitive biases and reward sensitivity. Appetite, 55, 61-68. http://dx.doi.org/10.1016/j.appet.2010.04.001.

Allison, D. B., Kalinsky, L. B., \& Gorman, B. S. (1992). A comparison of the psychometric properties of three measures of dietary restraint. Psychological Assessment, 4, 391-398. http://dx.doi.org/10.1037/1040-3590.4.3.391.

Boon, B., Vogelzang, L., \& Jansen, A. (2000). Do restrained eaters show attention toward or away from food, shape and weight stimuli? European Eating Disorders Review, 8, 51-58. http://dx.doi.org/10.1002/(SICI)1099-0968(200002)8:1<51:: AID-ERV306>3.0.CO;2-E.

de Jong, P. J., Koster, E. H. W., van Wees, R., \& Martens, S. (2010). Angry facial expressions hamper subsequent target identification. Emotion, 10, 727-732. http://dx.doi.org/10.1037/a0019353.

De Ruiter, C., \& Brosschot, J. (1994). The emotional Stroop interference effect in anxiety. Attentional bias or cognitive avoidance? Behaviour Research and Therapy, 32, 315-319. http://dx.doi.org/10.1016/0005-7967(94)90128-7.

Dobson, K., \& Dozois, D. (2004). Attentional biases in eating disorders. A metaanalytic review of Stroop performance. Clinical Psychology Review, 23 1001-1022. http://dx.doi.org/10.1016/j.cpr.2003.09.004.

Elfhag, K., \& Rössner, S. (2010). Weight loss maintenance and weight cycling. In P. G. Kopelman, I. D. Caterson, \& W. H. Dietz (Eds.), Clinical obesity in adults and children (3rd ed., pp. 351-365). Wiley-Blackwell.

Franken, I. H. A. (2003). Drug craving and addiction. Integrating psychological and neuropsychopharmacological approaches. Progress in Neuro-Psychopharmacology \& Biological Psychiatry, 27, 563-579. http://dx.doi.org/10.1016/S02785846(03)00081-2.

Gorman, B. S., \& Allison, D. B. (1995). Measures of restrained eating. In D. B. Allison (Ed.), Handbook of assessment methods for eating behaviors and weight-related problems. Measures, theory, and research (pp. 149-184). Thousand Oaks, CA, US: Sage Publications, Inc.

Grand, S. (1968). Color-word interference. An investigation of the role of voca conflict and hunger in associative priming. Journal of Experimental Psychology, 77, 31-40. http://dx.doi.org/10.1037/h0025759.

Herman, P. C., \& Polivy, J. (1980). Restrained eating. In A. J. Stunkard (Ed.), Obesity (pp. 208-225). Philadelphia, PA: Saunders.

Hollitt, S., Kemps, E., Tiggemann, M., Smeets, E., \& Mills, J. S. (2010). Components of attentional bias for food cues among restrained eaters. Appetite, 54, 309-313. http://dx.doi.org/10.1016/j.appet.2009.12.005.

Jeffery, R. W., Epstein, L. H., Wilson, G. T., Drewnowski, A., Stunkard, A. J., \& Wing, R R. (2000). Long-term maintenance of weight loss. Current status. Health Psychology, 19, 5-16. http://dx.doi.org/10.1037/0278-6133.19.Supp 11.5.
Kavanagh, D. J., Andrade, J., \& May, J. (2005). Imaginary relish and exquisite torture. The elaborated intrusion theory of desire. Psychological Review, 112, 446-467. http://dx.doi.org/10.1037/0033-295X.112.2.446.

Koster, E. H. W., De Raedt, R., Verschuere, B., Tibboel, H., \& De Jong, P. J. (2009). Negative information enhances the attentional blink in dysphoria. Depression and Anxiety, 26, E16-E22.

Lang, P.J., Bradley, M.M., \& Cutberth, B. N. (1999). International Affective Picture System (IAPS): Technical Manual and Affective ratings (Tech. Rep. No. A-5). Gainesville, University of Florida, Center for Research in Psychophysiology.

Mann, T., Tomiyama, A. J., Westling, E., Lew, A., Samuels, B., \& Chatman, J. (2007). Medicare's search for effective obesity treatments. Diets are not the answer. American Psychologist, 62, 220-233. http://dx.doi.org/10.1037/0003066X.62.3.220.

Most, S. B., Chun, M. M., Widders, D. M., \& Zald, D. H. (2005). Attentional rubbernecking. Cognitive control and personality in emotion-induced blindness. Psychonomic Bulletin \& Review, 12, 654-661.

Most, S. B., Smith, S. D., Cooter, A. B., Levy, B. N., \& Zald, D. H. (2007). The naked truth. Positive, arousing distractors impair rapid target perception. Cognition and Emotion, 21, 964-981. http://dx.doi.org/10.1080/02699930600959340.

Piech, R. M., Pastorino, M. T., \& Zald, D. H. (2009). All I saw was the cake. hunger effects on attentional capture by visual food cues. Appetite. http://dx.doi.org/ 10.1016/j.appet.2009.11.003.

Potter, M. C., Staub, A., \& O'Connor, D. H. (2002). The time course of competition for attention. Attention is initially labile. Journal of Experimental Psychology: Human Perception and Performance, 28, 1149-1162. http://dx.doi.org/10.1037/00961523.28.5.1149.

Schneider, W., Eschman, A., \& Zuccolotto, A. (2002). E-prime reference guide. Pittsburgh, PA: Psychology Software Tools.

Shapiro, K. L., Caldwell, J., \& Sorensen, R. E. (1997). Personal names and the attentional blink. A visual 'cocktail party' effect. Journal of Experimental Psychology: Human Perception and Performance, 23, 504-514. http://dx.doi.org/ 10.1037/0096-1523.23.2.504.

van Strien, T. Herman, C. P., Engels, R. C. M. E., Larsen, J. K., \& van Leeuwe, J. F. J. (2007). Construct validation of the restraint scale in normal-weight and overweight females. Appetite, 49, 109-121. http://dx.doi.org/10.1016/ j.appet.2007.01.003.

Veenstra, E. M., de Jong, P. J., Koster, E. H. W., \& Roefs, A. (2010). Attentional avoidance of high-fat food in unsuccessful dieters. Journal of Behavior Therapy and Experimental Psychiatry, 41, 282-288. http://dx.doi.org/10.1016/j.jbtep. 2010.02.006.

Wilson, C., \& Wallis, D. J. (2012). Attentional bias and slowed disengagement from food and threat stimuli in restrained eaters using a modified Stroop task. Cognitive Therapy and Research. http://dx.doi.org/10.1007/s1068-012-9451.

\section{Appendix A}

Reference numbers to images taken from the International Affective Picture System (IAPS; Lang, Bradley, \& Cuthbert, 2001).

\section{A.1. Threat stimuli}

\begin{tabular}{|c|c|c|c|c|c|c|c|c|c|c|c|c|}
\hline 2800 & 3000 & 3010 & 3015 & 3030 & 3053 & 3060 & 3061 & 3062 & 3063 & 3064 & 3071 & 3100 \\
\hline 3102 & 3110 & 3120 & 3130 & 3140 & 3168 & 3170 & 3261 & 3266 & 3301 & 3350 & 3550 & 6253 \\
\hline 6313 & 6350 & 6560 & 7361 & 9040 & 9331 & 9405 & 9570 & 9571 & 9800 & 9810 & & \\
\hline
\end{tabular}

\section{A.2. Neutral stimuli}

\begin{tabular}{|c|c|c|c|c|c|c|c|c|c|c|c|c|}
\hline 1440 & 1450 & 1463 & 1500 & 1510 & 1540 & 1590 & 1600 & 1601 & 1602 & 1603 & 1610 & 1620 \\
\hline 1630 & 1660 & 1670 & 1710 & 1720 & 1721 & 1722 & 1750 & 1810 & 1812 & 1920 & 1999 & 2050 \\
\hline 2070 & 2092 & 2200 & 2214 & 2279 & 2510 & 5410 & 5470 & 7001 & 7009 & 7010 & 7016 & 7018 \\
\hline 7020 & 7025 & 7030 & 7032 & 7034 & 7050 & 7052 & 7058 & 7090 & 7175 & 7211 & 7503 & 7508 \\
\hline
\end{tabular}

